\title{
Extradural dermoid tumours of the posterior fossa
}

\author{
J F Martínez-Lage, J Ramos, A Puche, M Poza
}

\begin{abstract}
Dermoid tumours in children usually occur in two locations: at the anterior fontanelle and on the occipital squama. An exceptional site of origin for a posterior fossa dermoid cyst is the extradural space. There are only six previous cases of this situation reported in the literature. A series of 103 subscalp and calvarial masses in children were reviewed and three children are reported with extradural dermoids of the posterior fossa, which communicated with the skin through midline occipital dermal sinuses. All three children were seen after the rapid growth or the formation of an abscess in a previously noted occipital subcutaneous mass present since birth. Although computed tomography or magnetic resonance imaging showed the dermal sinus and the intracranial tumour, these studies were unable to ascertain the intradural or extradural nature of the tumours, their exact origin only being established at operation. Histopathological study showed preclinical signs of infection in the two patients that had not yet formed an abscess. It is suggested that early neurosurgical treatment of these neoplasms should be done to prevent the development of severe intracranial infection. The previously reported simplicity of surgical removal of occipital extradural dermoids was not confirmed in this series. (Arch Dis Child 1997;77:427-430)
\end{abstract}

Keywords: cranial dermal sinuses; dermoid tumours; abscesses in dermoid cysts; dermoid cyst aetiology

'Virgen de la Arrixaca' University Hospital; Department of Neurosurgery

J F Martínez-Lage M Poza

Department of Pathological Anatomy J Ramos

Department of Neuropaediatrics A Puche

Correspondence and reprint requests to:

Dr Juan F Martínez-Lage, Regional Service of

Neurosurgery,

'Virgen de la Arrixaca'

University Hospital,

National Health Service,

El Palmar, E-30120 Murcia,

Spain.

Accepted 2 July 1997
The occurrence of cranial dermoids in children is well known. ${ }^{12}$ Dermoid cysts are often found at the anterior fontanelle and the occipital region of children. ${ }^{34}$ Anterior fontanelle dermoids have caused considerable discussion in the neurosurgical literature for two reasons: a presumed racial predominance in black people and a considerable concern about intracranial penetration, ${ }^{56}$ although at present no case of anterior fontanelle dermoid has been associated with a dermal sinus. ${ }^{4}$ On the other hand, dermoid tumours of the occipital region are often associated with congenital dermal fistulas and with severe intracranial infection in the form of meningitis or cerebellar abscess. ${ }^{7}$ Most posterior fossa dermal sinuses end blindly in the subcutaneous tissue, or are linked to intradural dermoids. ${ }^{8}$ For one of these sinuses to result in an extradural dermoid seems to be an exceptional event. A search of the current literature has disclosed only six cases of dermoids in this unique position. ${ }^{7-13} \mathrm{~A}$ previous report signalled that the clinical presentation of extradural dermoids is merely that of a discharging midline occipital sinus and that surgical removal is easy, ${ }^{10}$ which is in contradiction with our experience. The rarity of these extradural lesions, and the difficulties in diagnosis and treatment encountered in the management of these tumours have prompted us to report our cases.

\section{Patients and methods}

At our hospital we treated 103 children with scalp and calvarial masses during the period 1976-96. Twenty five (24\%) of these neoplasms were dermoid and epidermoid tumours (table 1). Five patients had dermoid cysts situated at the posterior cranial fossa. Two people were excluded from the survey: a 4 year old girl with an occipital dermal sinus and acute hydrocephalus who died shortly after external ventricular drainage, and an 18 year old woman with an occipital dermal sinus connected with an abscess in a cerebellar dermoid. We revised the medical records, studies of neuroimaging, operation protocols, and histopathological results of the remaining three patients who fulfilled the criteria of extradural dermoid cysts in the posterior fossa. ${ }^{10}$

PATIENT 1

A 27 month old girl with a subscalp occipital nodule noted at birth was seen because of rapid enlargement of the lesion during the previous three months. The only finding at examination was a reddened subcutaneous nodule $3 \mathrm{~cm}$ in diameter, which discharged pus through three small skin openings. Radiographs showed a small lytic defect of the skull with sclerosed margins. A computed tomogram showed a cystic soft tissue mass continuous with an intracranial lesion of similar characteristics (fig 1). The cyst wall enhanced partially after intravenous contrast infusion. The operation was performed on 21 September 1984. Total removal of a $3 \mathrm{~cm}$ whitish, encapsulated, mass was accomplished. The cyst was attached to the dura and was adherent to the occipital venous sinus, which bled profusely when the cyst was removed. Culture of the discharging

Table 1 Topographical distribution and sex of 25 subscalp dermoid tumours in children

\begin{tabular}{lll}
\hline Site & Boys & Girls \\
\hline Anterior fontanelle & 3 & 9 \\
Posterior fossa & 0 & 3 \\
Frontal & 3 & 5 \\
Temporal & 1 & 0 \\
Parietal & 0 & 1 \\
Total & 7 & 18 \\
\hline
\end{tabular}




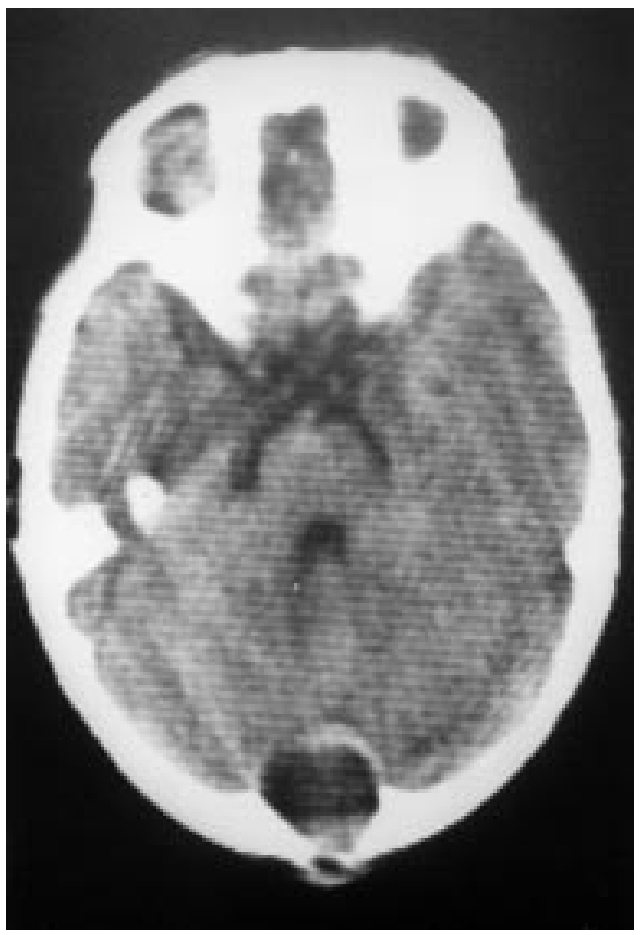

Figure 1 A computed tomogram of patient 1 showing an extradural cystic lesion in the posterior fossa communicating with a subcutaneous mass (reprinted from Martinez-Lage fF, Capel A, Costa TR, Pérez-Espejo MA. The child with a mass over its head: diagnostic and surgical strategies. Childs Nerv Syst 1992;8:247-52.)

material grew Staphylococcus aureus, and appropriate treatment was given. The girl required further surgery for treatment of a postoperative epidural empyema. Histopathological study of the excised tissues was consistent with the diagnosis of an abscess in a dermoid neoplasm. At the latest review the girl was asymptomatic and had no signs of a recurrence after a follow up period of 12 years.

PATIENT 2

A 6 month old girl was seen because of a small subcutaneous lump noted at birth, which caused no symptoms but that had enlarged during the previous month. Examination showed a small cutaneous midline orifice at some distance from the dome of an occipital subcutaneous tumour, which measured $3 \mathrm{~cm}$ in diameter. Skull radiographs showed a soft tissue mass and a lytic occipital osseous defect. Magnetic resonance imaging (MRI) showed two isointense lesions, one extracranial and the other intracranial, separated by bone, and a fistulous orifice (fig 2). The relation of the intracranial tumour with the dura mater could not be ascertained exactly. An operation was performed on 9 December 1992. The tumour and the fistula were removed through a small occipital craniotomy. During the dissection of the neoplasm from the occipital venous sinus there was considerable haemorrhage. Histopathology confirmed the diagnoses of cranial dermal sinus and dermoid tumour with a striking inflammatory component around the lesion's walls. The child made a good recovery and there is no evidence of recurrence after a follow up of four years.

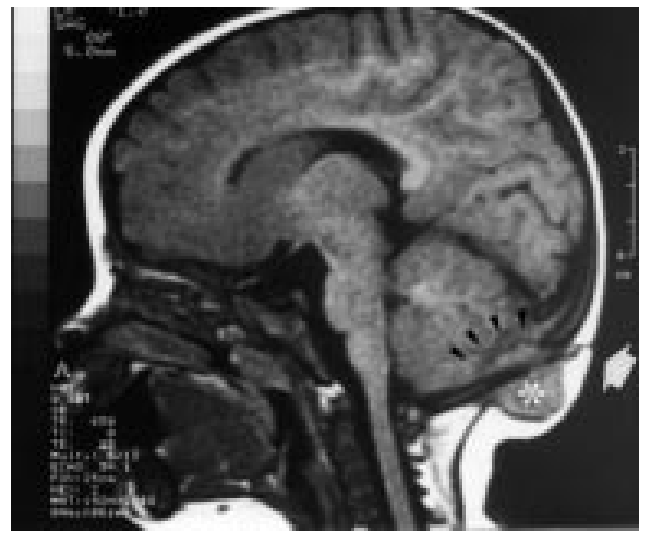

Figure 2 MRI of patient 2 showing intracranial (arrowheads) and extracranial (asterisk) isointense lesions separated by the occipital bone. Note the fistula ending on the surface of the occipital region (white arrow).

PATIENT 3

A 27 month old girl was brought for treatment of a subcutaneous lesion noted on the back of her head at birth. After a mild blow to the head, the mass had enlarged and the child frequently touched the swelling. Examination showed a 3 $\mathrm{cm}$ diameter subscalp nodule, and a separated small midline skin opening situated above it. Skull radiographs disclosed a multilobed, partially sclerotic, zone of bone lucency. MRI showed isointense extracranial and intracranial lesions separated by a thin zone of bone, which appeared to communicate with the skin through a bone gap (fig 3). The operation took place on 10 October 1996. An occipital craniotomy was required for total excision of the tumours and the fistula. The intracranial portion of the neoplasm appeared to arise from within the two layers of the dura mater. During dissection, the occipital venous sinus was torn causing a substantial haemorrhage. A histological examination showed a cyst lined by keratinised squamous epithelium, zones with abundant pilous follicles, and foreign body reactive granulomatous lesions (fig 4). The child's immediate recovery and her short term follow up have been uneventful.

\section{Discussion}

EMBRYOPATHOGENESIS

Epidermoid and dermoid tumours are thought to arise in the early stages of

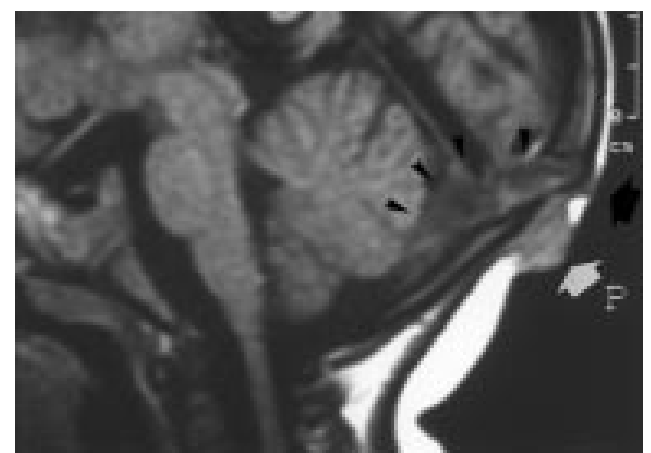

Figure 3 MRI of patient 3 showing a lesion that extends from the extradural space of the posterior fossa

(arrowheads) to an occipital dermal sinus (black arrow). There was also a subcutaneous swelling (white arrow) connected with the sinus. 


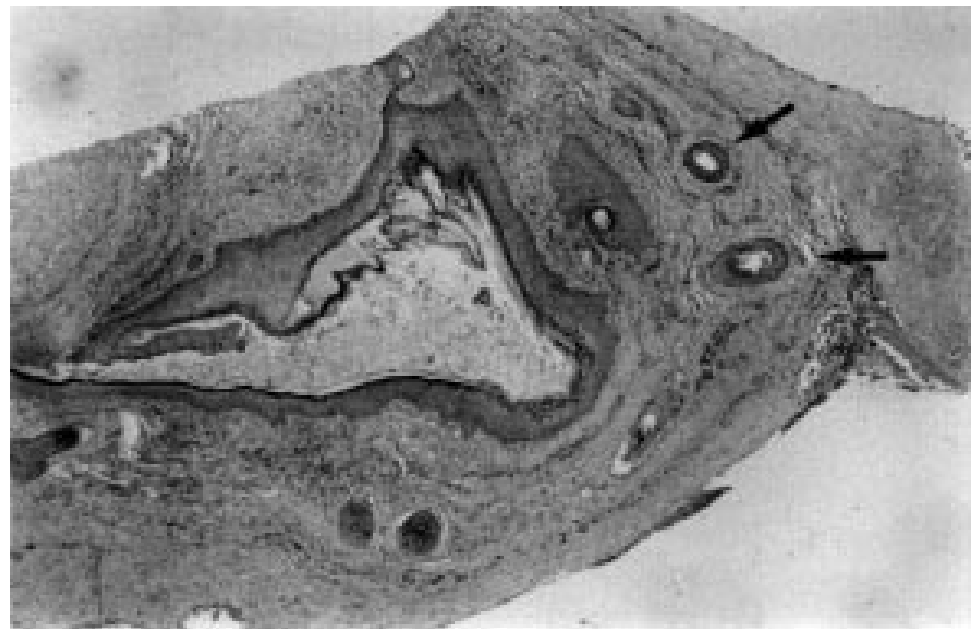

Figure 4 Section of the excised dermoid tumour: cystic cavity lined by squamous epithelium of epidermal type and cutaneous adnexes. Note the presence of hair follicles (arrows) in this slice (haematoxylin and eosin, original magnification, $\times 100)$.

embryonic development, between the third and fifth week of intrauterine life, probably due to faulty separation of the neuroectoderm and cutaneous ectoderm. As pointed out by Logue and Till, dermoid cysts of the posterior fossa tend to lie in the midline of the skull, whether outside or within the dura mater. ${ }^{10}$ This tendency to a midline position is probably related to the development of the falx and tentorium which occurs as an invagination of two folds of dura, and may draw fragments of the cutaneous ectoderm in with it. Another characteristic is that the attachment to the skin may be retained as a narrow tract lined by epithelium (the dermal sinus), and this links the cyst with the skin through an opening in the occipital bone. ${ }^{10}$ This connection with the surface permits extrusion of cyst contents to the exterior, and provides direct access for bacteria lying on the skin to the interior of the tumour.

OCCIPITAL DERMOIDS AND DERMAL SINUSES The first description of an occipital dermal sinus ending in a dermoid tumour of the posterior cranial fossa was made by Ogle in $1865 .^{814}$ Congenital dermal sinuses can arise anywhere in the midline of the body at any level of the craniospinal axis. ${ }^{8}$ These lesions have aroused special interest among paediatricians because they can extend into the cranial cavity, allowing passage of germs from the skin surface to the intracranial structures, and because they may be connected to congenital cell rest tumours growing within the central cavity. The most frequent location of these sinuses are the lumbosacral and occipital regions. ${ }^{8}$ Those presenting in the occipital region may end in the scalp, skull, extradural space, or within the cranial cavity. ${ }^{8}$ Those that extend to the meninges may end in the subarachnoid space or be connected to epidermoids or dermoids in the posterior fossa. Posterior fossa dermoids are usually situated in the midline, either in the cerebellar vermis or within the fourth ventricle. Congenital dermal sinuses may be discovered at birth as a small cutaneous pit, or they may present as a subcutaneous mass. They also may present with raised intracranial pressure or with intracranial infection (meningitis or abscess). The most frequent association of a dermal sinus of the occipital region is with a congenital tumour (dermoid or epidermoid) that is generally situated intradurally. ${ }^{8}$ In Wright's review of 127 cases of congenital dermal sinuses, 30 were located at the occipital region, and of these, three ended in the subarachnoid space or nervous tissue, two in the dura, one superficially, and 23 terminated in congenital tumours of cutaneous origin. ${ }^{8}$ The situation of the 23 (epi)dermoid tumours was intradural in 21 instances, with only two sinuses ending in extradurally located dermoids. The extradural location of dermoids appears to be most unusual. ${ }^{8}$ In Matson's series only one of 19 occipital dermal sinuses ended in an extradural dermoid. $^{7}$

EXTRADURAL DERMOIDS WITHIN THE POSTERIOR FOSSA

Logue and Till classified posterior fossa dermoid cysts into four groups depending on whether they were extradural or intradural, and on the degree of development of the dermal sinus, whether absent, partial, or complete: (1) extradural dermoid cyst with a complete sinus, (2) intradural dermoid cyst without a dermal sinus, (3) an intradural dermoid cyst with an incomplete dermal sinus, and (4) an intradural dermoid with a complete dermal sinus. ${ }^{10}$ With cysts lying extradurally, the occipital dermal sinus seems always to be complete, linking the tumour with the skin. A review of the current literature disclosed a few reports concerning extradural dermoids arising in the posterior fossa. Although they are mentioned in several

Table 2 Reported cases of extradural dermoid cysts of the posterior fossa

\begin{tabular}{|c|c|c|c|c|c|c|}
\hline No & Author & Age (years) & Sex & $\begin{array}{l}\text { Clinical } \\
\text { presentation }\end{array}$ & Surgery & Result/comments \\
\hline 1 & Martin and Davis ${ }^{9}$ & 2 & Male & Raised ICP^ & Yes & Interdural, cured \\
\hline 2 & Logue and Till ${ }^{10}$ & 2 & Male & Scalp mass & Five operations & Cured \\
\hline 3 & Matson $^{7}$ & 2.5 & Unknown & $\begin{array}{l}\text { Scalp mass, } \\
\text { meningitis }\end{array}$ & Yes & Cured \\
\hline 4 & Schijman $e t a l^{11}$ & 3 & Female & $\begin{array}{l}\text { Scalp mass, } \\
\text { meningitis }\end{array}$ & Yes & Interdural, epidermoid, cured \\
\hline 5 & Rubin et al ${ }^{12}$ & 27 & Male & Raised ICP & Yes & Torcular compression, cured \\
\hline 6 & Goffin $e t a l^{13}$ & 7 & Male & Scalp mass & Yes & Interdural, cured \\
\hline 7 & Present series & 2 & Female & $\begin{array}{l}\text { Scalp mass, } \\
\text { infection }\end{array}$ & Yes & $\begin{array}{l}\text { Sinus haemorrhage, epidural } \\
\text { empyema, cured }\end{array}$ \\
\hline 8 & Present series & 0.5 & Female & Scalp mass & Yes & Sinus haemorrhage, cured \\
\hline 9 & Present series & 2 & Female & Scalp mass & Yes & $\begin{array}{l}\text { Sinus haemorrhage, } \\
\text { interdural, cured }\end{array}$ \\
\hline
\end{tabular}


articles, ${ }^{315}$ clinical details were available for only six patients. ${ }^{79-13}$ Table 2 summarises the cases collected from the literature and those in our series. Patients' ages ranged from 6 months to 27 years (median 2 years), there were five women, and three men, the sex being unknown in one case. Clinical presentation was of a palpable subcutaneous mass in seven out of nine cases, raised intracranial pressure in two cases out of nine, and meningitis in three out of nine. A dermal sinus was recorded in seven out of nine cases. In our first patient, it was not clear on clinical or histological examination if the skin orifices were secondary to discharge of pus from an abscess in the dermoid or if they represented dermal sinuses of congenital origin. Diagnosis was established by the diverse radiological and imaging methods available at the time. The radiographic appearance was of a circular bone defect of varying diameter surrounded by a smooth sclerotic edge just below the inion. ${ }^{10}$ Computed tomography and MRI were the most useful methods of diagnosis, although we were unable to predict the intradural or extradural position of the dermoid in our patients. Angio-MRI is of paramount importance to determine the relation of the dermal sinus with the venous sinuses, given the vicinity of the torcular. Total removal of the sinus and tumour is the aim of treatment if permanent cure is to be achieved. Incomplete resection of the lesions results in tumour recurrence, as happened in one patient who required up to five procedures. ${ }^{10}$ In our experience, operation was far from simple, all of our patients bled profusely during the dissection of the cyst from the underlying dural sinuses, and one case was complicated by the accumulation of an epidural empyema which required reoperation. Although only one of our patients had obvious signs of infection at presentation, all three exhibited variable grades of inflammatory changes at microscopical examination. This fact suggests that if the lesions are not excised promptly they are at risk of developing overt intracranial infection in spite of the apparent barrier against infection provided by the dura mater. ${ }^{71} \mathrm{~A}$ point of interest is that the lesions tend to manifest themselves precociously, seven out of nine patients were younger than 3 years. Another important finding was the critical tumour size (about $3 \mathrm{~cm}$ ), most patients developed symptoms when the dermoids reached this dimension. In conclusion, we would like to recommend early surgical excision of extradural dermoid cysts originating at the posterior fossa, especially in view of the fact that they may become infected through the dermal sinus with which they are invariably associated.

We are indebted to Mr Saturnino Espín, at the hospital's department of photography, and to Mrs Mari Carmen G Navarro and Mr Antonio L Alarcón for secretarial assistance.

1 Ruge JR, Tomita T, Naidich TP, Hahn YS, McLone DG. Scalp and calvarial masses of infants and children. Neurosurgery 1988;22:1037-42

2 Martínez-Lage JF, Capel A, Costa TR, Pérez-Espejo MA. The child with a mass over its head: diagnostic and surgical strategies. Childs Nerv Syst 1992;8:247-52.

3 Peter JC, Sinclair-Smith C, DeVilliers JC. Midline dermal sinuses and cysts and their relationship to the central nervous system. Eur f Pediatr Surg 1991;1:73-9.

4 Crawford R. Dermoid cyst of the scalp: intracranial extension. $\mathcal{F}$ Pediatr Surg 1990;25:294-5.

5 Pannell BW, Hendrick EB, Hoffman HJ, Humphreys RP. Pannell BW, Hendrick EB, Hoffman HJ, Humphreys RP. Dermoid cysts

6 Martínez-Lage JF, Quiñonez MA, Poza M, Puche A, Casas C, Costa TR. Congenital epidermoid cysts over the anterior fontanelle. Childs Nerv Syst 1985;1:319-23.

7 Matson DD. Neurosurgery of infancy and childhood. Springfield: Thomas, 1969:96-112.

8 Wright RL. Congenital dermal sinuses. Prog Neurol Surg 1971;4:175-91.

9 Martin J, Davis L. Intracranial dermoid and epidermoid tumors. Archives of Neurology and Psychiatry (Chicago) 1943;49:56-70

10 Logue V, Till K. Posterior fossa dermoid cysts with special reference to intracranial infection. I Neurol Neurosurg Psychiatry 1952;15:1-12.

11 Schijman E, Monges J, Cracnaz R. Congenital dermal sinuses, dermoid and epidermoid cysts of the posterior fossa. Childs Nerv Syst 1986;2:83-9.

12 Rubin G, Scienza R, Pascualin A, Rosa L, DaPian R. CraniRubin G, Scienza R, Pascualin A, Rosa L, DaPian R. Crani-
ocerebral epidermoids and dermoids. Acta Neurochir (Wien) 1989;97:1-16.

13 Goffin J, Plets C, VanCalerbergh F, et al. Posterior fossa dermoid cyst associated with dermal fistula: report of two cases and review of the literature. Childs Nerv Syst 1993;9: 179-81.

14 Ogle J. Cases illustrating the formation of morbid growths, deposits, tumours, cysts, etc, in connection with the brain and spinal cord and their membranes. Br For Med-Chir Rev 1865;36:200-58 (cited in 8).

15 Guidetti B, Gagliardi FM. Epidermoid and dermoid cysts. Clinical evaluation and late surgical results. $f$ Neurosurg 1977;47:12-8. 